\title{
The Portrayal of Ideal Beauty Both in The Media and in the Fashion Industry and How These Together Lead to Harmful Consequences Such As Eating Disorders
}

\author{
Assistant Professor Dr. Gülçin İpek Kalender \\ Anadolu University, Yunus Emre Campus, Communication Sciences Faculty, Department of Communication \\ Design and Management, Eskisehir, Turkey,
}

\begin{abstract}
In today's world, women are frequently exposed to the message that "slim is beautiful" in diverse platforms such as women's magazines, advertisements, soap operas and on social media which often present women in ideal beauty standards. Seeing these images, which represent the ideal beauty over and over again in the media, make ordinary women to compare their body proportions with them and have upsetting emotions when they don't meet these standards, which are expected. Nevertheless, most of the time ordinary women are unaware of the fact that the media usually applies photo shop filters to the beautiful women images before conveying them and they also disregard the fact that some of the women who represent the ideal beauty have had some kind of plastic surgery. Thus, the media, which create a fantasy world with the ideal beauty, make ordinary women to feel envy towards this illusionary representation and lead them to take action by applying strict diet programs to feel light. However, young adolescent girls who are in a vulnerable age period are more easily affected by these images and feel discontent about their own bodies. The over-exaggerated slim women images often cause disorders in young adolescent girls' eating habits and sometimes lead to fatal illnesses such as anorexia and bulimia, as a result. Since they are living in a period of their lives in which peer acceptance is highly significant, young adolescent girls who want to look beautiful, start strict diets or they seldom eat during the day. Furthermore, they feel the stress of how they will lose weight in a short amount of time and they slowly become anorexia by controlling their appetite. The aim of this paper is to discuss how the media images of ideal beauty lead young adolescent girls to suffer from eating disorders by presenting a literature review.
\end{abstract}

Keywords: ideal beauty, media, being slim, young adolescent girls, eating disorders 
20-22 March, 2020

Berlin, Germany

\section{$10^{\text {th }}$ International Conference on Humanities, Psychology \& Social Sciences}

\section{Introduction:}

Today, the media continually tell women that their bodies have many imperfections and these can only be repaired with the help of cosmetics, plastic surgery, diet and exercise (Czerniawski, 2015, p. 17). Advertisements, fashion, and beauty products constantly indicate women that it is necessary for their bodies to have some kind of improvement, which creates major stress on women in return (Pompper, 2017, p. 32). Especially, the cosmetics industry emphasizes women that they need to consume beauty products in order to fix their physical appearance (Ringrow, 2016, p.13).

Beauty advertisements on women's magazines give the instructions of how a woman look better than her natural physical appearance by indicating that it has flaws such as body fat. Women are told that they need to get rid of their soft, loose and excess flesh immediately by using many cosmetic and beauty products since this is the only way that will help them to attain excellence (Bordo, 1993, p.191). The aim of these advertisements is to sell products and they tell women that in order to achieve perfection and flawlessness they need to consume these products (Pompper, 2017, p.88).

Moreover, the media always shows young women who are fabulous with their slim appearance in the advertisements of women's magazines, presents the impressive lifestyle of female celebrities who are slim in magazine programs, or displays the slim actresses in fashionable clothes in soap operas. The media, in fact, introduce the slender images of these famous women to the average women as the ideal beauty standards. From the perspective of hypodermic syringe theory, in other words, the mass society theory, the media influences women who are the passive receivers and absorbers of the messages that the media sends repetitively about the ideal beauty (Parekh and Schmidt, 2003, p.222).

From the viewpoint of objectification theory, when women are incessantly exposed to slim women images in the media and gaze them continually, they start to assess their own bodies by thinking that they can only fit in the society if they meet those appearance standards and they begin to evaluate their own bodies in a critical way (Betz and Ramsey, 2017, p. 19). Nevertheless, these images shown in the media are usually unrealistic because either the images have been undergone some process of photo shopping or the women who represent the ideal beauty in these images have had some kind of plastic surgery.

According to Wolf (2002, p.10) the Western world restricts the freedom of women with the beauty myth that it has created as this myth ultimately leads to physical obsessions with the body weight and facial appearance, and the yearning to control aging. The number of women who are completely satisfied with their bodies are very few because both the media and the fashion industry make women feel insecure about their bodies by making them see their imperfections with the perfect images that they use on the advertisements (Abel, deBruin and Nowak, 2010, p.13). 
20-22 March, 2020

Berlin, Germany $10^{\text {th }}$ International Conference on Humanities, Psychology \& Social Sciences

The Western world introduced and disseminated slenderness and being lean as worldwide standards of the ideal feminine beauty, even though what is considered beautiful used to

change in different societies throughout the time periods (Hua, 2013, p.168). In Westernized societies, women who cannot achieve this slim appearance undergo stress and suffer from conflict because they cannot meet the standards that are set and expected (Pompper, 2017, p.27). However, Richardson and Locks (2014, p.1-2) indicate that it is the culture which determines whether we are considered fat and thus there isn't a fixed understanding of the body, instead it is flexible in different contexts. Thus, a body, which is considered normal size in one society, might be considered fat or thin in another one.

Nevertheless, the unrealistic slim women images used in the advertisements as the ideal beauty to be attained by women causes eating disorders for some young adolescent girls as these images affect their perception about their own bodies. Thus the media causes vulnerable people, in this case, teenage girls to be influenced from these images as it associates thinness with being successful and becoming more acceptable among peers (Giordano, 2015, p.479). In other words, young adolescent girls think that if they become as thin as the fashion models or celebrities shown in the media, they will be more popular and lovable among their friends (Hawkins, et al., 2004, p.36).

Nevertheless, these young girls, who are affected from these unrealistic images, are not aware of how a healthy woman body should be like. In fact, it is the body mass index, which indicates the normal size of a human's body. The body mass index is calculated when the weight of a woman is divided to the squared of her height and women who are between 18.5 and $24.9 \mathrm{~kg} / \mathrm{m}$ are considered normal weight (Halliwell and Dittmar, 2008, p. 125).

Thus, these young adolescent girls cannot separate the idealized women images shown in diverse media such as the advertisements, women's magazines or magazine programs on TV from the daily life reality and as a result of their depression, they have eating disorders since they apply unhealthy diets to their bodies. This paper will discuss how the media and fashion industry portray the ideal beauty and will debate the elements presented by the media and fashion industry, which cause young adolescent girls to suffer from eating disorders.

\section{The Idealized Portrayal of The Feminine Body in the Fashion Industry and in the Media}

The fashion industry is the decision-maker of how the outlook of women will be like in each season of the year. The designers often design slim-fit clothes, which can be worn by women who have smaller waists and who are slender. Women who are only slim can wear the jeans, the dresses, and the skirts that are tightly fitting. Women who are plus size have difficulties in finding clothes that fit into their bodies comfortably. In fact, women like to shop clothes since this is a pleasurable activity, which increases their confidence, self-esteem and happiness because when they fit in their clothes, this makes them powerful (Parekh and Schmidt, 2003, p.235). 
20-22 March, 2020

Berlin, Germany $10^{\text {th }}$ International Conference on Humanities, Psychology \& Social Sciences

Therefore, being plus-size women is something annoying for women especially when nothing fits on their bodies. Nevertheless, the thing which is interesting is that a plus size woman, who has an average size and weight, isn't perceived fat by an ordinary person; however, it is the fashion industry which considers her as fat (Czerniawski, 2015, p. 7). In a way, the fashion industry subtly forces women to fit into much smaller sizes. Bordo (1993, p.140) mentions that the fashion industry has put forward slenderness on the stage for the last two decades and has made women obsessed with their weight, as they desire to be slim, tight and young just like the fashion models.

What is interesting is that not only women who want to buy the clothes in fashion stores, but also fashion models that try to get jobs in fashion shows have to watch their weight all the time. The media frequently disseminate the images of famous thin models wearing skinny clothes and this creates a misconception among women that "anorexic beauty", in other words, skinny bodies are more attractive than women having a normal shape of body (Giordano, 2007, p.103).

Before a few years ago, many luxury fashion brands used to give a priority to models that are size zero in their fashion shows. However, many models had difficulties in preserving their slim appearance. Therefore, some of these models in Turkey didn't eat any food before the fashion shows; instead they ate cotton, which doesn't have any calorie, to make their stomach feel full (Akdenizim.net, 2013). However, when an increase has been seen among the spread of illnesses such as anorexia and bulimia among models, a movement that tries to prevent the usage of size zero has become widespread in the fashion industry.

For instance, the French luxury fashion brands have arrived to the decision that size zero models don't look healthy, therefore they will not use size zero models at their shows anymore (NTV, 2017). On the other hand, just a few years ago, fashion models used to lose work opportunities because of not being a size zero (Czerniawski, 2015, p. 7). However, the increase in the diseases of anorexia and bulimia in recent years have led fashion brands to take precautions towards it.

Another supporter of this movement is Unilever, an international consumer goods company, which started the "Campaign for Real Beauty" with its Dove advertisements showing the real body proportions of women and prohibiting the usage of size zero models on its advertisements (Muspratt, 2007). The campaign aimed to show that women are beautiful with their natural body curves, skin and hair. The campaign tried to draw attention that extreme slimness isn't something that has to be achieved by women because it creates dissatisfaction and its consequences are self-destructive (Bahadur, 2014).

Dove's "Campaign for Real Beauty" is proud of the natural body proportions of women and portrays that women are beautiful with their natural skin and hair. The campaign is a celebration of joy for many women. The existence of this campaign is caring and supportive for many women because the campaign demonstrates the real depiction of women instead of their idealized portrayal. 
20-22 March, 2020

Berlin, Germany $10^{\text {th }}$ International Conference on Humanities, Psychology \& Social Sciences

Nevertheless, how the traditional and new media present the women bodies today are still mostly related with the ideal beauty. The ideal beauty tells women that their skin should be smooth and firm, their hair should not be grey and their bodies should be slim (Ringrow, 2016, p.32). The woman who represents the idealized femininity in the media is described as a white woman in early stages of her life and who has a slim body, and who comes from a good economic status and who seeks heterosexual relationships (Pompper, 2017, p. xvi).

For instance, in women's magazines, we mostly see representations of slimness in the advertisements because the advertising industry claims that slimness sell more products than fatness (Halliwell and Dittmar, 2008, p.123). Fashion models that are slim advertise the products and encourage other women into consumption by showing the activity of consumption as something, which liberates and empowers them while it entertains and fulfills them at the same time (Iqani, 2012, p.26). Young teenage girls who are affected from the celebrities in the advertisements have a tendency to shop more often and want to try new products frequently by giving importance to materialistic values (Banerjee and Dittmar, 2008, p.188).

In the advertisements of women's magazines, teenage girls often come across with the images of gorgeous thin female models who wear fashionable apparels and who are seen in popular districts, and the first thing they do is to compare their body image with theirs and most of these young adolescent girls feel inadequate as they wish that they had skinny legs like these models (Adomaitis and Johnson, 2008, p.189). Therefore, the representation of women in the media can be described as mythical since the media doesn't represent women as they naturally are, but wants them to fit in the ideal representation in which they are always defined as sexy, beautiful and feminine (Abel, deBruin and Nowak, 2010, p. 21).

According to Richardson and Locks (2014 p.39), women magazines can be considered as a club where women who buy the magazines learn the latest gossip about the celebrities who are both rich and famed; nonetheless, it is also an unpleasing activity because these magazines show that ordinary women aren't handling their lives satisfactorily as it continually give advices about beauty, health and relationships. Also, Abel, deBruin and Nowak (2014, p.181) underlines that while women's magazines create a feeling of community and approach to other women as an equal friend, on the contrary, they create myths about famous celebrity women with the codes that they use in advertisements, and thus these magazines usually lack the social identities taking place in actual life in them.

Furthermore, magazine programs in popular culture often broadcast the images of famous slim women who are stunning with their physical appearance, stylish hair, fashionable clothes and splendid lifestyle. In other words, young adolescent girls, who are exposed to the messages of the media about being slender many times, begin to stay away from their daily life reality gradually and they get lost in the dreamlike reality presented by the media instead (Hogan and Strasburger, 2008, p.13). However, the photo-shopped images of celebrities shown in these programs negatively influence many girls. As a result of this unreal representation shown on television and the Internet, these adolescent girls see their bodies as imperfect and this eventually creates "the desire to be thin" which is termed as anorexia nervosa (Giardono, 2007, p.2). 
20-22 March, 2020

Berlin, Germany $10^{\text {th }}$ International Conference on Humanities, Psychology \& Social Sciences

For instance, the weight of these slim models portrayed in these fashion advertisements are generally $15 \%$ less than the average weight of a woman and they don't represent the normal standards (Hawkins et al., 2004, p.36). Also, the Barbie doll, which represents the ideal feminine beauty as a toy, lacks 17 to $22 \%$ of the body fat of a normal size woman (Hua, 2013, p.172). In a way, just from very early ages, women are introduced to being slenderness with Barbie dolls. These dolls become a role model for the female children who want to look like them when they grow up. Females, who are introduced to these dolls during their childhood, want to groom, diet and shop just like the lifestyle shown in the Barbie dolls when they grow up (Richardson and Locks, 2014, p.35).

Teenage girls, who have a competition among their peers related with being considered beautiful, are easily influenced by the media images as they often take the celebrities as role models for themselves. Celebrities are famous people, who have gained fame as a result of seeing their faces numerous times in the media and of being talked about constantly in the media, due to their exciting and glittering lifestyle (Herwitz, 2008, p. 19). For instance, celebrities are often used in product advertisements because they are regarded as "a source of credibility" as they try to persuade people with their expertise (Silvera and Austad, 2004, p.1511).

Related with the ideal beauty, celebrities, who are singers, actresses or fashion models, demonstrate how a woman should be like to many adolescent girls, who often watch soap operas, music clips and magazine programs on television and in a way persuade them that these are the standards to be achieved. In other words, the media forms the meaning of femininity by showing the ideal image of a woman and it indicates how women should dress and how they should look (Schroeder, 2007, p. 15). In fact, celebrities seen in the advertisements usually sell an utopia with the products that they advertise as they try to convince the audience that buying these products will give them happiness, good feelings, satisfaction, social status and acceptance by peers (Abel, deBruin and Nowak, 2010, p.16).

Adolescent girls who see the photo shopped pictures of celebrities want to be as slim as the women that they see in the pictures by thinking that they are real representations, and they want to use the same cosmetic products and buy the same clothes as they think that if they become like them they will be more popular among their peers. Peer pressure has influence on teenage girls in choosing products such as clothes, and how to behave in a group, which social activities to participate and what kind of a boyfriend to have (Banerjee and Dittmar, 2008, p.191).

Also, there is one thing that young girls don't think through. In fact, each female identity is unique from each other because every women has her own experiences that she creates on her own and thus one cannot resemble the actuality of one woman to another (Pompper, 2017, $\mathrm{xv}$ ). However, most of the young adolescent girls in Turkey try to be like the celebrities or fashion models, instead of creating their own stories and lifestyles.

Furthermore, according to Wilcox and Laird (2000, p.279), two things can happen when a young adolescent girl looks at the image of a slender woman celebrity: One of them is that 
20-22 March, 2020

Berlin, Germany $10^{\text {th }}$ International Conference on Humanities, Psychology \& Social Sciences

she can identify herself with the image that she sees and imagines that she can look like her too and has a pleasurable moment, or she can compare her body with the celebrity who defines the beauty standards and has a disappointing moment.

Adolescent girls admire the pictures that they look at and then they have such a dilemma. On one hand, their inner voice says that "I want to be the same" I want to be just like her", on the other hand they know that this is something unobtainable, and thus it is very depressing (Coleman, 2012, p.101). In other words, young adolescent girls experience the pressure to be thin and then they have the conflict of how they will become thin (Pompper, 2017, p.27). Thus, with the aim of losing weight, they start to starve themselves. In the end, these girls gradually become underweight by becoming anorexic.

Therefore, feminism gives a struggle with the media in order to overcome the pressure of becoming thin which is pushed directly by the media and to see more positive representation of women's body in the media instead (Coleman, 2012, p.4). In other words, feminism tries to change the perspectives of the professionals working in the media and in the fashion industry, which often use slender women representations, in order to avoid the spread of illnesses such as anorexia nervosa and bulimia among women.

\section{The Lifestyle of Young Adolescent Girls and How They Have Eating Disorders}

During the span of their lives, the body of every woman undergoes a transformation. The feminine body continually changes and doesn't stay the same (Coleman, 2012, p.87). This is both related with the innate physical development of a woman's body and the food culture a woman is nourished in her family. When they are little babies, their mothers often feed girls so whether they will gain weight is up to how much their mothers will feed them during the day.

Sometimes, mothers who have concerns that their little babies will not grow up healthier feed their daughters in excessive amounts. However, this causes the baby to vomit the food given with the help of a spoon immediately since the stomachs of babies are small. It is found out that this behavior of mothers prepares a base for eating disorders in later stages of a woman's life. It is because the baby isn't fed when she is hungry therefore the baby can't feel her hunger, in other words, she can't distinguish her physical sensations (Giordano, 2005, p.143).

Adolescence is the period, when the bodies of teenagers go through a major and sudden change, and when teenagers are more worried with their physical appearance as they try to embrace their new looks (Hogan and Strasburger, 2008, p. 1). During this time, many girls in Turkey are generally unaware of how many calories that they need to take in a day because no specific education is given related with daily calorie consumption at schools and the food corners at shopping centers and cafes on popular districts often sell high calorie food that address to the taste of young adolescents. 
20-22 March, 2020

Berlin, Germany

\section{$10^{\text {th }}$ International Conference on Humanities, Psychology \& Social Sciences}

Young adolescents who are exposed to the food advertisements on television and the Internet are tempted to try the food advertised when they go out. The food advertisements containing brand symbols, artificial appearances, gestures and jingle sounds influence young adolescents unconsciously and lead them to give a reaction, which is trying the food (Cohen, 2014, p.86).

During the day, adolescent girls in Turkey frequently go to the school canteens and often eat junk food. At the weekends, they often stick around at popular fast food restaurants with their friends. There, they usually eat hamburgers, pizzas and French fries, and most of the time they drink carbonated beverages. Instead, young adolescent girls need to get only 50\% their energy from carbohydrates daily and these carbohydrates should be complex and should be gotten from fibrous food instead of simple sugar (Merdol, 2017, p.163).

Therefore, the weight of adolescent girls is usually above than the average, and if they don't change their eating habits towards healthy nutrition, they become plus size girls. However, in Western cultures, having body fat is not something desired because it means that one cannot control her appetite and thus she lacks self-discipline (Czerniawski, 2015, p.11). This is partly because the Western world defines fatness as something primitive, uncultured and out of control and a person's physical size gives these subtle messages to the receivers (Abel, deBruin and Nowak, 2010, p.183).

In the meantime, the media continually spreads the message that "women who are slim are beautiful" in these diverse platforms, and young adolescent girls who are exposed to this message starts to compare their body proportions with the slim women images which are presented as the ideal beauty in the media. Especially, in women's magazines there are numerous images of slim models or of celebrities, description of diets, and advertisements of diet products, and this means that if a woman or girl doesn't look slim she is considered as a failure among her peers (Giordano, 2005, p.102).

In other words, in women's magazines, teenage girls are persistently exposed to the perfect bodies of thin models that are attractive and flawless, and when they compare their bodies with these models, this creates not only anxiety, but also depression (Adomaitis and Johnson, 2008, p.184). Thus, many young adolescent girls even with a normal body size have dissatisfaction about their weight in Turkey.

Therefore, seeing these idealized images in the media, over and over again, becomes an upsetting issue for many adolescent girls, which affects their psychology and causes them to dislike their bodies, in the end. However, the slim women images set such standards, which are impossible to be reached by young adolescent girls, and they not only affect these girls' self-esteem, but also create stress and conflict at the same time (Pompper, 2017, p.75).

Also, in terms of gender, the researches indicate that women are more concerned with their body image than men as men tend to focus more to their physical capabilities rather than their physical appearance (Borland and Akram, 2007, p.312). Even though men aren't really obsessed with slenderness as a beauty ideal just as much as women do, they want their girlfriends or wives to be slim in contrast (Bordo, 1993, p.204). 
20-22 March, 2020

Berlin, Germany

\section{$10^{\text {th }}$ International Conference on Humanities, Psychology \& Social Sciences}

Thus, teenage girls who have dissatisfaction about their body image, start applying strict diets to their bodies without the control of dieticians or their parents, in order to be seen attractive for the opposite sex. They think that if they don't eat anything during the day, they will lose weight significantly and this way they will reach the slim body image, which is shown as the ideal beauty in the media easily.

In fact, anorexia nervosa starts with the decision of the young adolescent girls to diet in order to have a dominant sense of control over their bodies (Parekh and Schmidt, 2003, p.221). In other words, Bordo (1993, p.146-150) indicates that anorexia nervosa begins with the young adolescents' desire to destroy their appetite and to become a master of their own bodies where they rule their own kingdom. This feeling of self-control gives the power to the anorexic girls to treat their bodies as the way they want. They are the rulers of their own bodies, which are metaphorically their own kingdom. In a way, they try to discipline their body with eating less and they like having this strict control in their own hands.

Having been influenced from the images of celebrities in the media, these teenage girls, who are discontent about their body shape, start to skip breakfasts during the mornings; they eat lesser than their normal portions during the lunches and dinners. They either start shock diets or starve themselves during the day. In the meantime, they start exercising in long hours without eating anything at all. Griffiths et al. (2018, p. 188) mention the term "fitspiration" in order to emphasize that the adolescent girls, who exercise, also admire the muscular, fit and lean body shape of celebrities. Teenage girls suddenly have the misperception that these slim celebrity women are admired by so many people so if they achieve a similar body type their peers will appreciate them as well (Wang, 2010, p.52).

Moreover, the social lives of teenage girls are negatively influenced because of their strict meal schedule. They cannot participate all the social events because they think that it will spoil their diets. When they go out with their friends, they have stress about what to order and they always end up ordering low-calorie food. Because of having the control of what they will eat during the day, these adolescent girls constantly try to control the impulses of their body and they suffer themselves because of the rigid meal schedule that they apply to their bodies (Giordano, 2007, p.153). Moreover, Bordo (1993, p.163-171) highlights that the desire to control the body, having mastery over the body and disciplining the body emotionally are all part of the masculine language and they are associated with masculine characteristics, and thus it is the male will inside of these anorexic girls that causes them to act this way.

Anorexia is named as a "beauty sickness" because young adolescent girls give a struggle to reach unattainable body perfection since they are obsessed with reaching this ideal by using all their emotional energy for it (Matheson, 2017, p.9). Also, the researches indicate that young girls who have a low body focus strive to be much thinner than they actually are as these girls try to achieve a much lower weight that they don't really need since they are slim already (Lokken, et al. 2003 cited Borland and Akram, 2007, p. 314). Bordo (1993, p.160) mentions that anorexic girls have the image of a girl craving for food all time, feeling hungry constantly and they are afraid that if they just take a bite from the food they want, they won't be able to say no to themselves and will eat too much, thus they start dieting severely by repressing their emotions. 
20-22 March, 2020

Berlin, Germany $10^{\text {th }}$ International Conference on Humanities, Psychology \& Social Sciences

While anorexic girls think that limiting their calorie intake is the only solution to keep their form, bulimic girls think that purging is the only solution to have control over their weight (Michel and Willard, 2003, p.30). In other words, some of the adolescent girls cannot give up food easily just like anorexic girls and these girls usually consume carbohydrates most of the time. Thus, they become bulimia, which means the loss of the feeling of satiety because of being dependent on carbohydrates (Giordano, 2007, p. 82).

According to Michel and Willard (2003, p.31) there are a couple of factors, which cause young adolescent girls to suffer from anorexia and bulimia and these are biological, cultural and psychological factors. First of all, inherit characteristics, in other words, genetic characteristics are a basis for these illnesses. Secondly, thinness and fitness shown as ideal beauty with the media images lead to these illnesses. Thirdly, personality and emotional features such as perfectionism, obsessions, anxiety, and low self-esteem cause these illnesses.

However, all of these attempts to lose weight are in fact destructive for a person's health and these girls don't think about the consequences of how their life will be after, instead they try to maintain their lightness. Eating little portions during the day, in fact, risks their life. Therefore, these young adolescent girls usually faint and they are drip-fed in the emergency rooms of the hospitals in the end.

\section{Conclusion and Discussion:}

Particularly, in the last two decades, women who read women's magazines, watch magazine programs and soap operas on TV, use the Internet and social media have started to be influenced from the Western ideal beauty standards introduced by the media, from all angles, more. However, teenage girls, who cannot separate the unrealistic representations of glamorous slim women images in the media from daily life reality, have started to have eating disorders in return, due to their confusion and major stress. These adolescent girls feel themselves inadequate due to their lower self-esteem and they are negatively influenced by the illusionary representation of slender women in the media, which are very difficult to be attained. Therefore, in order to cope with eating disorders, the parents of young adolescent girls should take some certain precautions.

According to Derenne and Beresin (2006, p.260), in order to protect teenage girls, their parents should educate them about the unrealistic media representations and messages, should limit their exposure to the media by suggesting different activities helping to increase selfesteem, should counsel them in order to eat more healthy food by preparing healthy meals and snacks, should direct them to have dinner together as a family, and should recommend them to do more moderate exercise by planning their physical activity. In addition, parents should educate their girls about the dangers of anorexia and they shouldn't wait long until their girls start to show severe symptoms and they should motivate their girls to get medical help (Goldberg, 2018).

Furthermore, parents should monitor young adolescent girls' media usage by telling from which sites to get good information, should also discourage conversations related with being 
20-22 March, 2020

Berlin, Germany $10^{\text {th }}$ International Conference on Humanities, Psychology \& Social Sciences

fat and physical appearances, and should lead young adolescent girls to have more intellectual activities such as art, music and writing (Derenne and Beresin, 2018, p.132). Furthermore, parents should support their girls by being a role model for them, and should create a network for them where other people also care about them (Goldberg, 2018).

Also, the media and fashion industry should use more diverse representations of women without giving a damage to women's health, to their well-being as a human and to their daily experience related with eating food (Coleman, 2012, p.4) In order to overcome the ideal thin women representation of the media, some of the fashion brands have recently started to extend their sizes by adding plus-size women collections to their seasonal clothing collections and have started to show plus-size models on their advertisements to have diversity (Matheson, 2017, p. 61).

Thus, young adolescent girls should love their bodies and sizes, and they shouldn't think that they need to fit into the thin, young ideal body image seeming to be valued in the society (Derenne and Beresin, 2018, p. 129). In other words, teenage girls who have anorexia shouldn't enter into unhealthy behaviors because of the unrealistic ultra-slim women images shown by the media. Instead, their parents should help them to preserve a normal weight by giving them support and directing them to get counseling. Also, when they engage with intellectual activities these girls' self-esteem will be increased and once they get both emotional and medical support, these girls will be at peace with their bodies.

\section{References}

1. Abel, S. deBruin, M. and Nowak, A. (2010). Women, Advertising and Representation. Beyond Familiar Paradigms. New Jersey: Hampton Press.

2. Adomaitis, A. D. and Johnson, K. P. (2008). Advertisements: Interpreting Images Used to Sell Young Adults. Journal of Fashion Marketing and Management: An International Journal, 12 (2): 182-192. DOI:10.1108/13612020810874872

\section{Akdenizim.net (2013, October 30). Şanlı: "Bazı Mankenler Zayıf Kalmak İçin Pamuk} Yiyiyor". Retrieved from:

http://www.akdenizim.net/saglik/sanli-bazi-mankenler-zayif-kalmak-icin-pamuk-yiyiyorh20568.html

4. Bahadur, N. (2014, January 21). Dove 'Real Beauty' Campaign Turns 10: How A Brand Tried To Change The Conversation About Female Beauty. Huffpost. Retrieved from: https://www.huffingtonpost.com/2014/01/21/dove-real-beauty-campaign-turns10_n_4575940.html

5. Banerjee, R. and Dittmar, H. (2008). What is beautiful and who is "cool"? Consumer culture and socialization. Helga Dittmar (Ed.). Consumer Culture, Identity and Well-Being. The Search for the 'Good Life' and the 'Body Perfect'. (173-197). New York: Psychology Press. 
20-22 March, 2020

Berlin, Germany $10^{\text {th }}$ International Conference on Humanities, Psychology \& Social Sciences

6. Betz, D. E. and Ramsey, L. R. (2017). Should women be "All About That Bass?": Diverse Body-Ideal Messages and Women's Body Image. Body Image, 22: 18-31. DOI: 10.1016/j.bodyim.2017.04.004.

7. Bordo, S. (1993). Unbearable Weight. Feminism, Western Culture and The Body. Berkeley: University of California Press.

8. Borland, H. and Akram, S. (2007). Age is No Barrier to Wanting to Look Good: Women on Body Image, Age and Advertising. Qualitative Market Research: An International Journal, 10 (3): 310-333. DOI:10.1108/13522750710754335

9. Cohen, D. A. (2014). A Big Fat Crisis. New York: Nation Books.

10. Coleman, R. (2012). The Becoming of Bodies. Manchaster: Manchaster University Press.

11. Czerniawski, A. M. (2015). Fashioning Fat. New York: New York University Press.

12. Derenne, J and Beresin, E. (2018). Body Image, Media and Eating Disorders - a 10-Year Update. Acad Psychiatry, 42: 129-134. DOI: 10.1007/s40596-017-0832-z

13. Derenne, J. L. and Beresin, E.V.(2006). Body Image, Media and Eating Disorders. Academic Psychiatry, 30 (3): 257-261. DOI: 10.1176/appi.ap.30.3.257

14. Giordano, S. (2007). Understanding Eating Disorders. Conceptual and Ethical Issues in the Treatment of Anorexia and Bulimia Nervosa. New York: Oxford University Press.

15. Giordano, S. (2015). Eating Disorders and The Media. Curr Opin Psychiatry, 28 (6): 47882. DOI: $10.1097 /$ YCO.0000000000000201

16. Goldberg, J. (2018, August 3). Can You Prevent Anorexia? Retrieved from: WebMD Medical Reference,

https://www.webmd.com/mental-health/eating-disorders/anorexia-nervosa/prevent-anorexianervosa\#1

17. Griffiths, S., Castle, D., Cunnigham, M., Murray, B. B., and Barlow, F. K. (2018). How Does Exposure To Thinspiration and Fitspiration Relate To Symptom Severity Among Individuals With Eating Disorders? Evaluation of A Proposed Model. Body Image, 28: 187195. https://doi.org/10.1016/j.bodyim.2018.10.002

18. Halliwell, E. and Dittmar, H. (2008). Does size matter? The impact of ultra-thin media models on women's body image and on advertising effectiveness. Helga Dittmar. (Ed.). Consumer Culture, Identity and Well-Being. The Search for the 'Good Life' and the 'Body Perfect'. (121-146). New York: Psychology Press. 
20-22 March, 2020

Berlin, Germany $10^{\text {th }}$ International Conference on Humanities, Psychology \& Social Sciences

19. Hawkins, N., Richards, P.S., Granley, H. M. and Stein, D. M. (2004). The Impact of Exposure to the Thin-Ideal Media Image on Women. Eating Disorders, 12 (1): 35-50. DOI: $10.1080 / 1064026049026775$

20. Herwitz, D. A. (2008). The Star As Icon: Celebrity in the Age of Mass Consumption. New York: Columbia University Press.

21. Hogan, M. J. and Strasburger, V. C. (2008). Body Image, Eating Disorders and the Media. Adolesc Med State Art Rev., 19 (3): 521-46.

22. Hua, W. (2013). From Barbie Doll to the Korean Wave. Buying Beauty. Hong Kong: Hong Kong University Press. Retrieved from: https://www.jstor.org/stable/j.ctt2854d9.12

23. Iqani, M. (2012). Consumer Culture and the Media. Magazines in the Public Eye. New York: Palgrave Macmillan.

24. Matheson, M. (2017). Women's Body Image in the Media: An Analytical Study of Recent Body Image Movements across Media Platforms. In BSU Honors Program Theses and Projects. Item 251. Retrieved from: http://vc.bridgew.edu/honors_proj/251

25. Merdol, T. K. (2017). Genel Beslenme. Eskişehir: Anadolu Üniversitesi.

26. Michel, D. M. and Willard, S. G. (2003). Why Someone Develop an Eating Disorder? When Dieting Becomes Dangerous. New York: Yale University Press. Retrieved from: https://www.jstor.org/stable/j.ctt1nq785.9

27. Muspratt, C. (2007, May 9). Unilever Bans 'Size Zero' Models in Ads. The Telegraph. Retrieved from: https://www.telegraph.co.uk/finance/markets/2808653/Unilever-banssize-zero-models-in-ads.html

28. NTV (2017, September 6). Fransız Moda Şirketleri 'Sifir Beden'i Yasakladı. Retrieved from: https://www.ntv.com.tr/galeri/yasam/fransiz-moda-sirketleri-sifir-bedeniyasakladi,D2UDCAa9iEmfRLtUEWORQw/hBYClogzBkqzTrxL1oPeIA\#hBYClogzBkqzTr xL1oPeIA

29. Parekh, F. S. and Schmidt, R. A. (2003). In Pursuit of An Identity - Fashion Marketing and The Development of Eating Disorders. British Food Journal, 105, 4-5: 220-238. $10.1108 / 00070700310477022$

30. Pompper, D. (2017). Rhetoric of Femininity. Female Body Image, Media, and Gender Role Stress / Conflict. London: Lexington Books.

31. Richardson, N. and Locks, A. (2014). Body Studies. New York: Routledge 
20-22 March, 2020

Berlin, Germany $10^{\text {th }}$ International Conference on Humanities, Psychology \& Social Sciences

32. Ringrow, H. (2016). The Language of Cosmetics Advertising. London: Palgrave Pivot.

33. Schroeder, S. K. (2007). Popüler Feminizm. İstanbul: Bağlam Yayıncılık.

34. Silvera, D. H. and Austad, B. (2004). Factors Predicting The Effectiveness of Celebrity Endorsement Advertisements. European Journal of Marketing, 38, 11-12: 1509-1526. $10.1108 / 03090560410560218$

35. Wang, X. (2010). More Than Just Anorexia and Steroid Abuse: Effects of Media Exposure on Attitudes Toward Body Image and Self-Efficacy. Atlantic Journal of Communication, 18: 50-62. DOI: 10.1080/15456870903210089

36. Wilcox, K. and Laird, J. D. (2000). The Impact of Media Images of Super-Slender Women on Women's Self-Esteem: Identification, Social Comparison, and Self-Perception. Journal of Research in Personality 34, 278-286. https://doi.org/10.1006/jrpe.1999.2281

37. Wolf, N. (2002). The Beauty Myth. How Images of Beauty Are Used Against Women. New York: Harper Perennial. 